\title{
Modelling and simulation of deformation behaviour during drying using a concept of linear difference method
}

\author{
Thomas Schnabel $^{1} \cdot$ Hermann Huber $^{1}$. \\ Alexander Petutschnigg ${ }^{1,2}$
}

Received: 24 November 2015/Published online: 8 March 2017

(C) The Author(s) 2017. This article is published with open access at Springerlink.com

\begin{abstract}
This study deals with the development of a two-dimensional model to simulate the deformations in wood samples during the wood drying process for the evaluation of the drying quality. The samples cut from sapwood of beech were used to analyse the moisture content distribution of the samples at two different drying conditions. A new concept based on a linear difference method was developed to use the moisture content distribution of the samples for the simulation process to predict deformation due to casehardening. The real deformations of the prongs were compared with the simulated ones for further improvements. The results show that the model can be used to simulate the deformations independently from different drying times and drying conditions. A good comparison between real and simulated changes in deformation was found for the drying process at constant climate conditions. The results provide a useful basis for further investigations on the modelling and simulation of the deformation of the samples due to different drying processes.
\end{abstract}

\section{Introduction}

Moisture loss of wood during the drying process comprises among other things changes in dimension. Associated with this deformation certain strain formations in the wood occur. One of the challenges during the wood drying process is to minimise the arising gradient of drying stresses. Further, the prediction of the deformations and strains is possible. In this study, a novel approach for modelling

Thomas Schnabel

thomas.schnabel@fh-salzburg.ac.at

1 Department of Forest Products Technology and Timber Construction, Salzburg University of Applied Sciences, Marktstraße 136a, 5431 Kuchl, Austria

2 BOKU University of Natural Resources and Life Sciences, Konrad Lorenz-Straße 24, 3430 Tulln, Austria 
and simulating the changes in wood dimension during the wood drying process is examined.

It is a fact that below fibre saturation point (FSP) wood will shrink or swell in relation to its change in moisture content. This change in dimension of a wood sample is anisotropic and results on the one hand from the formation of wood material (e.g. difference in density, anatomical structure or wood chemistry) itself (Almeida and Hernández 2006; Bosshard 1956; Hinterstoisser et al. 1992; Pang and Herritsch 2005; Perré 1997; Ugolev 1976, 2014; Vintila 1939). On the other hand, the process of water absorption or desorption can produce a gradient of moisture content in the wood because the changes in moisture content on the surface are faster than the changes in the wood material (Siau 1984; Skaar 1988). A major change in humidity or moisture content leads to significant internal stresses (Svensson and Toratti 2002). This behaviour is one limiting point in wood drying. The higher the differences between the average moisture content in the wood and the equilibrium moisture content in the drying chamber the higher is the gradient of moisture content over the cross section, and this behaviour may lead to casehardening of the wood material, which is a result of plastic deformation (e.g. creeping) of the wood (Perré and Passard 2007). Many studies deal with the determination or estimation of stress development during the wood drying process (Allegretti and Ferrari 2008; Honfi et al. 2014; Lazarescu and Avramidis 2008; Perré and Passard 1995; Ranta-Maunus et al. 2001; Tarvainen et al. 2006; Ugolev and Skuratov 1992; Vanek 1986, 1991; Welling 1988; Welling and Fortuin 1989), whereas only limited information on deformation caused by shrinkage was found in literature (Dahlblom et al. 1996; Perré 2011). Dahlblom et al. (1996) mentioned the possibility of finite element methods to simulate the deformation process during the wood drying process. The real deformation of small lamella of the wood surface and the simulated distortion showed good conformity. The concept of multiscale modelling extends the requirements of computational resources and applied mathematics and can indicate different fields of observations (Perré 2011; Perré et al. 2012). For the modelling and simulation process, the anisotropic shrinkage of wood can be analysed on four different levels, molecular, ultrastructural, microstructural and macrostructural (Pang 2002). On the other hand, the quality of kiln dried wood can be assessed by using the slicing tests methods (prong or cup test) according to the EDG-recommendations of the European Drying Group (www.timberdry.net) or ONR CEN/TS 14464 (2010) standard for industrial applications. However, this method is wood material and time-consuming. In order to minimise the sample preparation work and to avoid that parts of the drying batch are destroyed by cutting samples for slicing tests, suitable simulation tools of shrinkage deformations concerning casehardening based on residual stress, stretched surface and dry shell in the wood (Ranta-Maunus et al. 2001) could be useful for practical applications.

Based on these considerations, the following two hypotheses were formulated in this study:

1. The simulation of the deformation is possible by using only the moisture content distribution. 
The shrinkage in one anatomical direction (e.g. tangential) of wood can be expected as linear in subareas (Pang and Herritsch 2005; Almeida et al. 2008). Therefore, a concept of linear difference method can be used to predict the deformation of wood during the drying process. Perré and Passard (2007) divided the existing strains due to the wood drying into three parts, the elastic, viscoelastic and mechanosorptive deformations. The elastic part is not determinable using the slicing test. On the other hand, the viscoelastic and mechanosorptive deformations of the wood samples are detectable. In this case, deformations are retained and the "frozen" strains cannot balance in the wood boards (Ugolev 2014). The assumption is that the moisture content distribution in wood samples can allow a better insight into the development of deformation and stress in the wood during the drying process.

2. The simulation process can be used to analyse the appearance of viscoelastic and mechanosorptive deformations due to the wood drying process.

For the optimisation of the drying process, the clarification of the material properties when casehardening (e.g. viscoelastic and mechanosorptive deformations) occurs is important. If the difference of the moisture distribution in the wood board is very high, then the probability of non-elastic distortion is also very high.

To verify the two hypotheses, the real and simulated displacements during wood drying were analysed. On the one hand, the prong test sample was used to analyse the deformations in the samples and on the other hand the information of the moisture content distribution in the wood samples was employed to simulate the deformations during wood drying at constant climate conditions.

\section{Experimental}

\section{Wood species and sample preparation}

In this study, samples from quarter sawn boards of beech (Fagus sylvatica [L.]) with dimensions of $400 \times 80 \times 40 \mathrm{~mm}^{3}$ were used. The initial moisture content of the samples was above $35 \%$. The end grains of the samples were coated using an aluminium foil bonded to the wood surface with PUR resin to prevent too fast drying on these sides.

\section{Drying conditions and moisture measurements}

Twelve samples of beech wood were dried simultaneously at constant climate conditions. To simulate a conventional drying process, a standard climate chamber (Binder KBF 240, Germany) was used for drying eight samples at $85{ }^{\circ} \mathrm{C}$ and $15 \%$ relative humidity $(\mathrm{RH})$ as well as four samples at $85{ }^{\circ} \mathrm{C}$ and $30 \% \mathrm{RH}$.

After various hours of drying, one sample of the climate chamber was selected and removed to determine checking and to measure deformation as well as measure the moisture content (MC) distribution. 
The samples were cut into halves and before cutting the prongs, a grid with a mesh width of $5 \mathrm{~mm}$ was sprayed on the end grain for a detailed analysis of the changes. After taking a picture of the labelled end grain, a prong sample was cut with a thickness of $10.0 \mathrm{~mm}$ and again photographed.

The moisture content distribution of the drying samples was determined by cutting off another slice of the end grain next to the prong slice which was divided into 25 sections $\left(6 \times 15 \mathrm{~mm}^{2}\right.$ or rather $\left.8 \times 15 \mathrm{~mm}^{2}\right)$ to get detailed information on the MC distribution. The MC of each section was determined applying the oven dry method according to ÖNORM EN 13183-1 (2004).

\section{Software}

MATLAB $\subset$ R2014a software packages were used for the analysis of the data and simulation of the deformation during the different wood drying processes.

\section{Results and discussions}

\section{Development of the deformation model}

An overview of the sample preparation and the necessary reduction of the complexity of this study are shown in Fig. 1. The prong sample was broken up by singular elements and their four bar elements to simplify the description of the

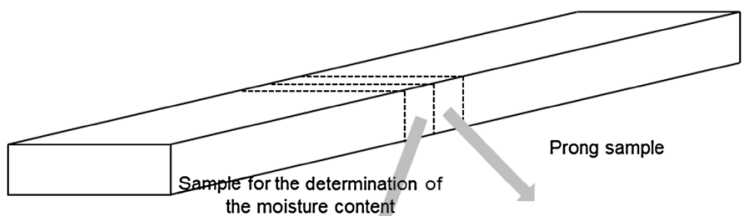

the moisture content
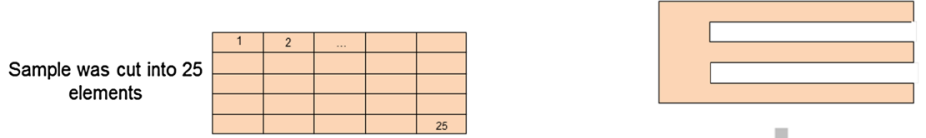

Slicing of the prong

sample

The moisture content of each element was determined and was used for the modelling and simulation process.

For the modelling the prong sample was divided into 17 elements

The moisture content of the four bar elements was estimated.
One element was separated into 4 bar elements, which were used for the modelling and simulation process

Fig. 1 Illustrated process of sample preparation and modelling 
system. It can also be seen that the sample for the MC determination and the prong test sample were adjacent. An equal moisture content distribution of both samples can be assumed.

The described procedure was performed for each sample in this study and divided into two processes, (1) determination of the moisture contents of the samples and (2) modelling of the moisture content of the four bar elements of the singular elements of the prong sample (cf. Fig. 1). This detailed modelling approach is shown in Fig. 2. The following functions of the theoretical MC of the bar elements are assumed for every element, which simplifies the complexities of the real sample.

In this connection, a distinction of cases was necessary to be able to calculate the theoretical MC of the four bar elements of the 17 elements of the prong samples.

If the values of the moisture content of the neighbouring elements exist then Eq. (1) is used for the calculation of the bar elements. If there is no adjacent wooden element, the $\mathrm{MC}$ of the element is equal to the MC of the relevant bar element.

$$
e_{i, j}=\frac{\left(u_{i, j}+u_{i, j+1}\right)}{2}, s_{i, j}=\frac{\left(u_{i, j}+u_{i+1, j}\right)}{2}, w_{i, j}=\frac{\left(u_{i, j}+u_{i, j-1}\right)}{2}, n_{i, j}=\frac{\left(u_{i, j}+u_{i-1, j}\right)}{2}
$$

The values of the theoretical MC of the bar elements were used for the further simulation process of the changes in dimensions of the bar elements. However, the shrinkage of wood demands further consideration. Therefore, the following assumptions were established for the development of the 2-dimensional model. The fibre saturation point (FSP) was set at 30\% MC. The changes in MC above 30\% do not result in shrinkage of the wood. The changes in MC below 30\% lead to an individual shrinkage in length of the bar elements (Fig. 3).

In addition, the shrinkage is influenced by radial and tangential orientations. Based on the considerations of the real proportion of the radial and tangential orientation, the shrinkage value was calculated. For the modelling and the simulation process of the deformation of each prong sample in this study, the differential shrinkage value (ds) used was 0.0025 .

Therefore, the differences in MC of each bar element are a function of the real MC in the bar element and the average of the moisture content $(\bar{M})$ of the samples, which is the equilibrium moisture content (EMC) of the samples. If the samples

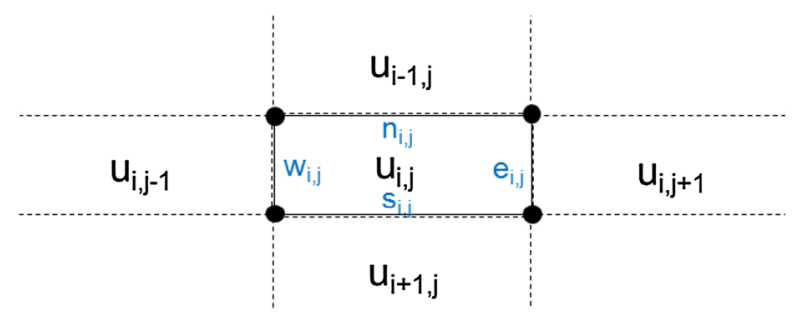

Fig. 2 One element and its neighbouring elements used for calculations of the theoretical MC of the four bar elements, where $u_{i, j}$ is the value of the moisture content of one element, $n_{i, j}, e_{i, j}, s_{i, j}$ and $w_{i, j}$ are the calculated values of the moisture contents of the bar elements, respectively 


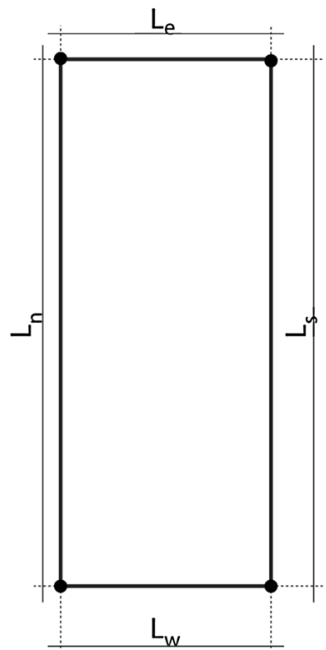

before shrinkage

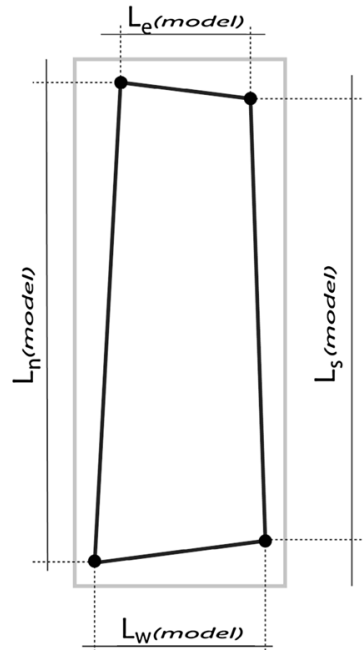

after shrinkage

Fig. 3 Sketch of the deformation of the four bar elements due to drying process

were covered with aluminium foil for $24 \mathrm{~h}$ according to ONR CEN/TS 14464 (2010), the moisture content of the sample has the tendency to equalise possible differences over the cross section. The calculation is expressed as:

$$
d \mathrm{M}=M-\bar{M}
$$

where $\mathrm{d} M$ is the matrix of the difference in moisture content of the singular elements before and after deformation, $M$ is the matrix of the moisture content measured before deformation, and $\bar{M}$ is the average moisture content of the wood samples in equilibrium state (after deformation). The changes in length of the bar elements can be expressed as:

$$
L_{(\text {model })}=L+\mathrm{d} M * L * \mathrm{~d} s
$$

where $L_{\text {(model) }}$ is the matrix of the changed length of the bar element due to shrinking, $L$ is the matrix of the length of the initial state of the model. The shrinking behaviour is assumed linear, so that the deformation is interpolated linearly over the whole element. The solution values of Eq. (3) represent the new lengths of the bar elements of the modelling samples. Based on these results of every bar element all singular elements had to be translated and rotated to place them in the right position at the boundaries of the connected elements in the prong sample.

\section{Evaluation of the model and simulation tool}

The MC of the samples was analysed from different wood drying processes at various times. Figure 4 shows a graphical evaluation of the MC distribution of selected samples after various drying times. 
The asymmetric distribution of the MC can be explained by the ambient conditions in the climate chamber used and the random positioning of the samples. The air ventilation between the samples was not uniform. However, this behaviour is negligible for the objectives in this study because only the numerical simulation process of the shrinkage deformation was evaluated and not the wood drying method. The samples with MC distributions (Fig. 4) were used to depict the real deformations (e.g. casehardening) after $24 \mathrm{~h}$ storage time according to ONR CEN/ TS 14464 (2010), which are shown in Fig. 5. It can be observed that deformations occurred after $1 \mathrm{~h}$ of the drying process. This behaviour of the real and simulated samples demands further consideration. Based on the distribution of the MC (Fig. 4), the curvature of the slices of the prong samples should point outside. Therefore, this displacement of the samples is not consistent with the results from literature (e.g. Perré and Passard 2007). On the one hand, the sample has the trend to equalise possible differences of the MC distribution. The assumption about the thin layers of this prong sample are that the thin outer layer of the prong samples swells during the $24 \mathrm{~h}$ storage time, whereas the thin inner layer shrinks. This leads to a deformation in the opposite direction. On the other hand, when the prong samples were cut, the deformation occurring immediately after the separating cut, pointed slightly outside.

Moreover, the middle section of the prong test was cut off so that the deformations of the samples were not restrained.

To validate the approach in this study, the comparison between the real deformation and the simulated changes in the sample size of the beech sample dried in a laboratory climate chamber is shown in Fig. 5 and in Table 1. It is recognisable that the simulation of the deformation effects and the actual changes during the wood drying process are comparable.

Due to the relatively high drying temperature $\left(85^{\circ} \mathrm{C}\right)$, some ductile set could have happened and some internal stress could have been relieved by cracking.

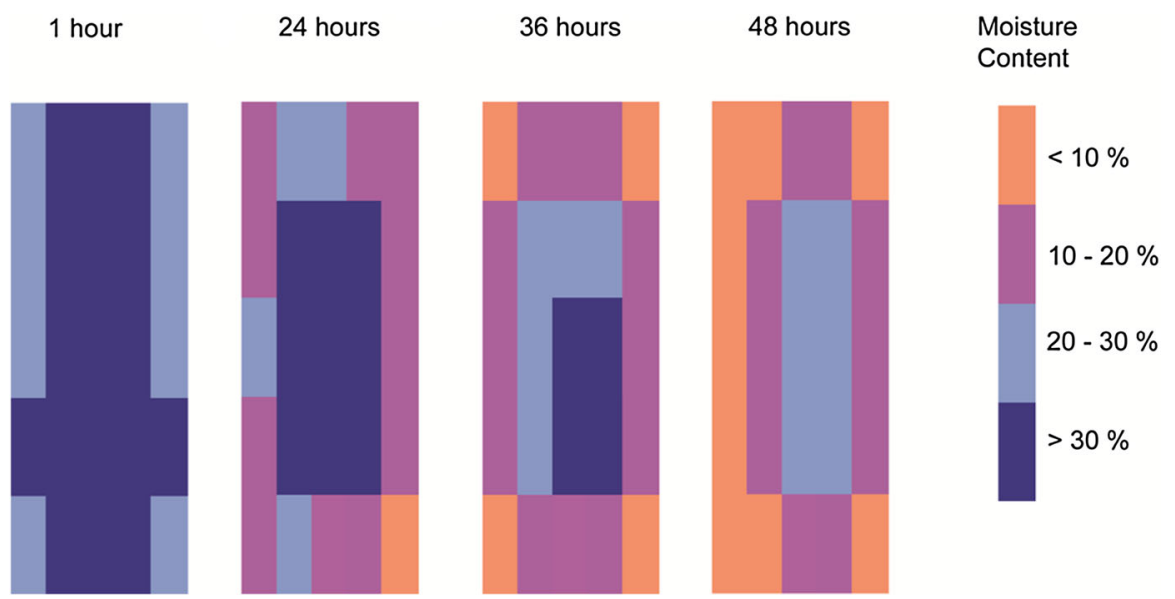

Fig. 4 Sketch of cross sections of different beech sapwood samples, indexed by the changes in MC during the drying process (initial MC was approx. 35\%) 
1 hour
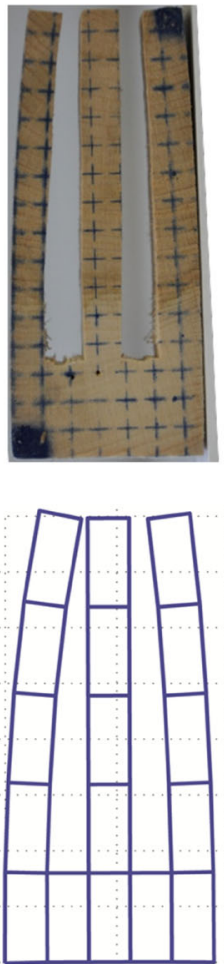

24 hours
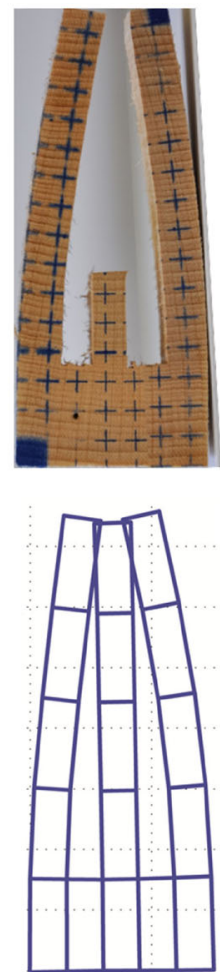

36 hours
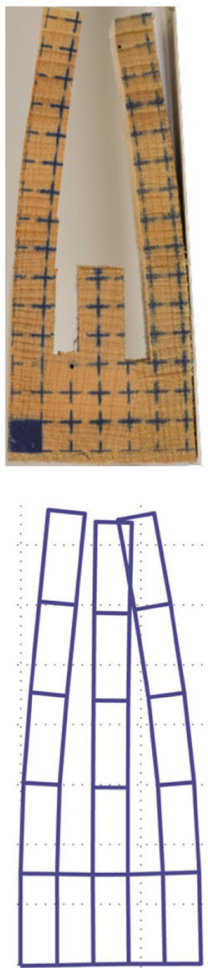

48 hours
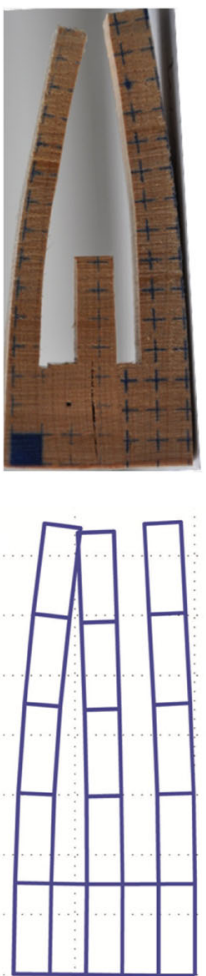

Fig. 5 Comparison between the real shrinkage deformation after $24 \mathrm{~h}$ storage according to ONR CEN/ TS 14464 (2010) and the numerical simulation of the prong samples at various drying process times

Table 1 Comparison of the real and simulated deformation of the prongs

\begin{tabular}{lll}
\hline Limit of deformation grading $(\mathrm{mm})$ & \multicolumn{2}{l}{ Classification of prong samples } \\
\cline { 2 - 3 } & Real & Simulated \\
\hline $0.0-5.0$ & 5 & 5 \\
$5.1-10.0$ & 5 & 6 \\
$10.1-15.0$ & 2 & 1 \\
$>15.0$ & 0 & 0 \\
\hline
\end{tabular}

Meanwhile cracks might have been formed if the stress exceeded the wood strength; however, the analysis of the cracks was not the research task in this study and was not considered for the modelling and simulation process.

The model to simulate the prong deformation on the basis of MC distribution works fairly well for beech [Fagus sylvatica (L.)] at the two different wood drying conditions of $85{ }^{\circ} \mathrm{C}$ and $15 \% \mathrm{RH}$ and $85{ }^{\circ} \mathrm{C}$ and $30 \% \mathrm{RH}$, respectively. However, 
there are still some challenges to optimise the modelling and simulation method for practical applications. When using accurate moisture measurement equipment and accurate measuring design (e.g. distribution of the measurement points), the necessary data of the MC distribution is already available during the drying process to predict probable drying stresses or to alter the process parameter.

Nevertheless, the aim of this study was fulfilled by showing the potential for a two-dimensional simulation of real deformation due to the wood drying process. The prediction of the prong deformation (casehardening) can save time as there is no need to wait for $24 \mathrm{~h}$ to get the results for the wood drying quality. The simulation model developed enables an adaptive process control by online measuring of the actual moisture content distribution, which was analysed by Welling (1986), in order to achieve a planned drying quality.

\section{Conclusion}

The samples showed various changes in the MC distribution of the cross section depending on the state of the drying process. Further, the determined drying quality was affected by the MC.

Modelling and simulation processes for the prediction of 2-dimensional deformations of wood during drying are well developed. Information about the MC values and the differential shrinkage value are suitable to predict the deformation of the prong samples used for the determination of the drying quality. Therefore, the two proposed hypotheses can be approved. The model can be used to simulate the deformations independently from different drying times (e.g. 1-48 h) and both constant drying conditions $\left(85^{\circ} \mathrm{C}\right.$ and $15 \% \mathrm{RH}$ as well as $85{ }^{\circ} \mathrm{C}$ and $30 \%$ $\mathrm{RH})$. A good comparison between the real and the simulated changes in deformation was found for both drying processes. This modelling and simulation method was suitable to determine the wood quality for the drying conditions used.

These results provide a useful basis for further investigations on the modelling and simulation of the deformation of the samples due to different drying processes. Further focus should be on drying processes under changing climate conditions to confirm this result. By identifying the MC distribution of the samples online during the drying process, the realistic deformation of the wood samples can be predicted within a short time. Therefore, it is not necessary to wait $24 \mathrm{~h}$ for the evaluation of the wood deformation due to the drying process according to EDG-Guidelines (www.timberdry.net) and ONR CEN/TS 14464 (2010).

Acknowledgements Open access funding provided by FH Salzburg - University of Applied Sciences. The authors gratefully acknowledge the support of the Austrian Research Promotion Agency (FFG) under Grant No. 839080.

Open Access This article is distributed under the terms of the Creative Commons Attribution 4.0 International License (http://creativecommons.org/licenses/by/4.0/), which permits unrestricted use, distribution, and reproduction in any medium, provided you give appropriate credit to the original author(s) and the source, provide a link to the Creative Commons license, and indicate if changes were made. 


\section{References}

Allegretti O, Ferrari S (2008) A Sensor for direct measurement of internal stress in wood during drying: experimental tests toward industrial application. Dry Technol 26:1150-1154

Almeida G, Hernández RE (2006) Changes in physical properties of tropical and temperate hardwoods below and above the fiber saturation point. Wood Sci Technol 40:599-613

Almeida G, Assor C, Perré P (2008) The dynamic of shrinkage/moisture content behaviour determined during drying of microsamples for different kinds of wood. Dry Technol 26:1118-1124

Bosshard HH (1956) Über die Anisotropie der Holzschwindung (On the anisotropy of wood shrinkage). Holz Roh Werkst 56:285-295 (In German)

Dahlblom O, Ormarsson S, Petersson H (1996) Simulation of wood deformation processes in drying and other types of environmental loading. Ann Sci For 53(4):857-866

Hinterstoisser B, Weingärtner J, Praznik W (1992) Influence of wood drying processes on the carbohydrate matrix of wood of picea abies. In: Proceedings of 3rd IUFRO international conference, Vienna, pp 217-221

Honfi D, Mårtensson A, Thelandersson S, Kliger R (2014) Modelling of bending creep of low- and hightemperature-dried spruce timber. Wood Sci Technol 48:23-36

Lazarescu C, Avramidis S (2008) Drying related strain development in restrained wood. Dry Technol 26:544-551

ÖNORM EN 13183-1 (2004) Moisture content of a piece of sawn timber-Part 1: determination by oven dry method. Austrian Standards, Vienna

ONR CEN/TS 14464 (2010) Sawn timber-method for assessment of case-hardening. Austrian Standards, Vienna

Pang S (2002) Predicting anisotropic shrinkage of softwood Part 1: theories. Wood Sci Technol 36:75-91

Pang S, Herritsch A (2005) Physical properties of earlywood and latewood of Pinus radiata D. Don: anisotropic shrinkage, equilibrium moisture content and fibre saturation point. Holzforschung 59:654-661

Perré P (1997) Image analysis, homogenization, numerical simulation and experiment as complementary tools to enlighten the relationship between wood anatomy and drying behavior. Dry Technol 15:2211-2238

Perré P (2011) A review of modern computational and experimental tools relevant to the field of drying. Dry Techol 29:1529-1541

Perré P, Passard J (1995) A control-volume procedure compared with the finite-element method for calculating stress and strain during wood drying. Dry Technol 13:635-660

Perré P, Passard J (2007) Stress development. In: Perré P (ed) Fundamentals of wood drying, European COST. A.R.BO.LOR, Nancy, pp 243-271

Perré P, Rémond R, Colin J, Mougel E, Almeida G (2012) Energy consumption in the convective drying of timber analyzed by a multiscale computational model. Dry Technol 30:1136-1146

Ranta-Maunus A, Forsén H, Tarvainen V (2001) Analysis of case hardening. In: Proceedings of the 3rd workshop of COST Action E15 on softwood drying to specific end-uses, 11-13 June 2001, Helsinki, Finland, pp 1-10

Siau JF (1984) Transport processes in wood. Springer, Berlin

Skaar C (1988) Wood-water relations. Springer, Berlin

Svensson S, Toratti T (2002) Mechanical response of wood perpendicular to grain when subjected to changes of humidity. Wood Sci Technol 36:145-156

Tarvainen V, Ranta-Maunus A, Hanhijärvi A, Forsén H (2006) The effect of drying and storage conditions on case hardening of scots pine and Norway spruce timber. Maderas Cienc Technol $8: 3-14$

Ugolev BN (1976) General laws of wood deformation and rheological properties of hardwood. Wood Sci Technol 10:169-181

Ugolev BN (2014) Wood as natural smart material. Wood Sci Technol 48:553-568

Ugolev BN, Skuratov NV (1992) Stress-strain state of wood at kiln drying. Wood Sci Technol 26:209-217

Vanek M (1986) Trocknungsspannungen: Spannungsermittlung bei einer Buchentrocknung mittels Dehnungsmeßstreifen (Drying stress: stress analysis during beech drying process using resistance strain gauges). Holzforsch Holzverw 38:36-42 (In German) 
Vanek M (1991) Kontinuierliche Ermittlung von Trocknungsspannungen mittels Biegemomentmessung (Continuous determination of drying stresses by means of bending moment measurement). Holzforsch Holzverw 43:22-25 (In German)

Vintila E (1939) Untersuchungen über Raumgewicht und Schwindmaß von Früh- und Spätholz bei Nadelhölzern (Studies on the volumetric weight and shrinkage value of early- and latewood in conifers). Holz Roh Werkst 2:345-357 (In German)

Welling J (1986) Kontinuierliche Messungen von Holzfeuchte während der Schnittholztrocknung (Continuous measurements of wood moisture profiles during a drying process). Holz Roh Werkst 44:361 (In German)

Welling J (1988) Die modellmäßige Erfassung von Trocknungsspannungen während der Kammertrocknung von Schnittholz (A model for the determination of drying stresses during kiln drying of lumber). Holz Roh Werkst 46:295-300 (In German)

Welling J, Fortuin G (1989) Überprüfung berechneter Trocknungsspannungs_-Verteilungen durch einen experimentellen quantitativen Spannungsnachweis. (Verification of calculated stress distributions by experimental determination of drying stresses). Holz Roh Werkst 47:243-247 